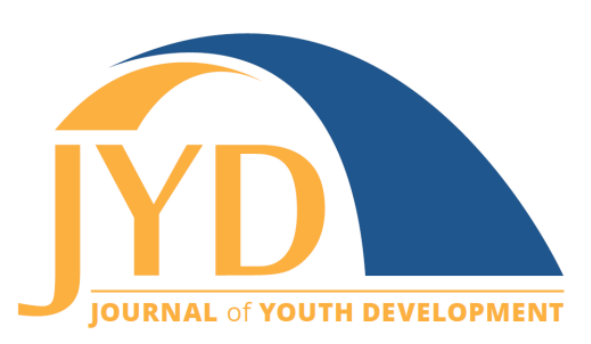

http://jyd.pitt.edu/ | Vol. 16 Issue 2-3 DOI 10.5195/jyd.2021.1138 | ISSN 2325-4017 (online)

\title{
International Positive Youth Development: Challenges and Opportunities in Policy and Practice
}

\author{
Lisa A. Lauxman \\ Independent Consultant and JYD Publications Committee Member \\ lisa.lauxman@gmail.com \\ Thomas Archibald \\ Department of Agriculture, Leadership, and Community Education; Virginia Tech \\ tgarch@vt.edu
}

Elizabeth M. Dowling

Tufts University, Institute for Applied Research in Youth Development

elizabeth.dowling@tufts.edu

\section{Cassandra Jessee}

International Center for Research on Women

cassandra.jessee@gmail.com

\section{Abstract}

This special issue of the Journal of Youth Development on international positive youth development brings together diverse perspectives of research, practice, and policy regarding the challenges and opportunities facing international efforts to promote the positive development of youth. To represent a plurality of perspectives on international PYD, the authors sought to represent a variety of continents, countries, genders, races, ethnicities, sectors, and levels of experience with publishing. There is also variety in the types of articles such as case studies, presentations of frameworks and curricula, letterstyle commentary by youth, and cutting-edge research methodologies and studies. A few key themes frame the volume, including (a) diversity in definitions of youth and operationalizations of PYD; (b) the multifaceted and multidimensional ways in which PYD is integrated into different sectors, domains, and types of programmatic and organizational contexts; and (c) the importance of and need for an accessible evidence base of PYD informed by rigorous science. Thought leader commentaries are interspersed in the beginning, middle, and end of the issue. The articles represent the current state of the field of PYD internationally with an outlook toward the future and how the integration of PYD research and practice can enhance contributions of youth to equity, social justice, and democracy.

(cc) EY New articles in this journal are licensed under a Creative Commons Attribution 4.0 License. This journal is published by the University Library System, University of Pittsburgh and is cosponsored by the University of Pittsburgh Press. The Journal of Youth Development is the official peer-reviewed publication of the National Association of Extension 4-H Youth Development Professionals and the National AfterSchool Association. 


\section{International Positive Youth Development}

Key words: international positive youth development, evidence base, cross-sectoral, gender, youth voice, civic engagement, conflict and crisis, integration of research and practice, LMIC, specificity principle

\section{Introduction}

This special issue brings together diverse perspectives of research, practice, and policy regarding the challenges and opportunities facing international efforts to promote the positive development of youth. The positive youth development (PYD) revolution that began in research communities in high income countries (HICs) and programs in the late 1990s has extended across the globe to low- and middle-income countries (LMICs). Increasingly, governmental agencies, non-governmental organizations, research institutions, foundations, and multilateral organizations are working to leverage and strengthen the capacities and well-being of a growing "youth bulge" by implementing PYD research and practice into their individual and collective development efforts. While progress has been made in scaling PYD globally few resources are available that synthesize the dynamic energy and creativity of international PYD innovations and collaborations into a single volume of peer-reviewed journal articles. This issue, rooted in the Journal of Youth Development's mission to bridge research and practice in PYD, seeks to do just that. Our hope is this volume, with its 20 articles representing a diverse range of policies, programs, research projects, and voices, can serve as a thorough and relatively comprehensive compendium of lessons learned and promising approaches in the field of international PYD, as well as a roadmap for future directions.

Diversity and inclusion are critical to this special issue. To represent a plurality of perspectives on international PYD, the editors were intentional to invite and include authors representing a variety of continents, countries, genders, races, ethnicities, sectors, and levels of experience. We also sought out and curated a variety of types of articles to include, such as case studies, presentations of frameworks and curriculum, letter-style commentary by youth, and research methodologies and studies.

Despite this intentionality, and much to the chagrin of the editors, it is impossible to capture the breadth of international PYD programming and research within one special issue. While this issue's intent is to move forward understanding about and motivate the effectiveness, scale, and sustainability of international PYD efforts, the articles within it represent a small snapshot of the thousands of programs being implemented around the world that intentionally or unintentionally promote the positive development of youth or the many research studies aimed at better understanding what works for youth related to PYD. There are many topics that are 


\section{International Positive Youth Development}

represented here that deserve their own special issue, such as the need for relevant and accessible PYD employment training and future directions in research methods. We also acknowledge there are other highly relevant and critically important aspects of PYD not addressed in this issue. For example, there is nothing specifically related to food insecurity, LGBTQ+ programming or research, or how to effectively address systemic racism which challenges the healthy development of so many young people around the world. Despite these gaps in content, we hope the special issue catalyzes and informs future international PYD research, programming, funding, and reporting efforts.

A few key themes framed our conceptualization of the volume, including (a) diversity in definitions of youth and operationalizations of PYD, (b) the multifaceted and multidimensional ways of PYD research and programming, and (c) the importance of and need for an accessible evidence base of PYD informed by rigorous science. A brief description of each of those themes is provided here to further inform the reader.

\section{Intentionally Inclusive of Diverse Definitions of Youth and Operationalizations of PYD}

The notion of "youth" is a socially and contextually-mediated construct. It is constituted, experienced, and perceived differently in relation to age, gender, race, ethnicity, national origin, marital status, economic activity, and more. For example, many governmental and multilateral organization policy documents assign different age ranges to the category of youth. In this volume, various definitions of youth are included and represented. Likewise, we allowed for variation in how PYD was operationalized and defined. However, there were some salient descriptions of PYD that guided our editorial approach. In particular:

- The Federal Interagency Working Group on Youth Programs (IWGYP), a collaboration of 21 United States' federal departments and agencies that support youth, has created the following definition (Interagency Working Group on Youth Programs, n.d.):

- PYD is an intentional, prosocial approach that engages youth within their communities, schools, organizations, peer groups, and families in a manner that is productive and constructive; recognizes, utilizes, and enhances young people's strengths; and promotes positive outcomes for young people by providing opportunities, fostering positive relationships, and furnishing the support needed to build on their leadership strengths. 


\section{International Positive Youth Development}

- USAID, through YouthPower Learning (YouthPower, n.d.), refined a definition reflecting the range of international contexts:

- PYD is both a philosophy and an approach to youth development. Positive youth development engages youth along with their families, communities and/or governments so that youth are empowered to reach their full potential. PYD approaches build skills, assets and competencies; foster healthy relationships; strengthen the environment; and transform systems.

- The work of Richard Lerner and his colleagues (for example, see Lerner et al., 2015) frame PYD in a relational developmental systems approach that assumes that all young people have strengths, and all contexts have positive assets. When the strengths of youth are combined with positive ecological assets, then positive, healthy development may occur over time.

We hope readers will note the salience of these definitions and perspectives throughout the volume while still appreciating and learning from the varied framing of PYD applied by different authors.

\section{The Multifaceted and Multidimensional Nature of Global PYD Research and Programming}

PYD research and programming are integrated into different sectors, domains, and types of programmatic and organizational contexts in a variety of ways. From a USAID perspective, the sectors include democracy, human rights and governance (DRG), education, gender equality and women's empowerment, global health inclusive of sexual and reproductive health (SRH), water and sanitation (WASH), agriculture and food security, economic growth and trade inclusive of workforce development and employment, and contexts of humanitarian assistance and working in crises and conflict and innovation, along with technology, innovation, and research. Organizational contexts engaged in PYD efforts include public-private partnerships, government, non-governmental entities, research institutions, donors, and funders.

Increasingly, those contexts are working in more highly integrated and collaborative ways. Young people are also being engaged more fully and intentionally into program development and design and into monitoring, evaluation and learning (MEL) efforts. The IWGYP outlined three PYD research domains including conceptual issues, data sources and indicators, and program implementation and effectiveness. This special issue provides examples of PYD's integration across many sectors and contexts. 


\section{Building an Accessible Evidence Base of PYD Framed in Rigorous Science}

A guiding motivation for the editors to develop this special issue was to contribute to efforts to bridge the divide that exists between the PYD research and practitioner communities. The special issue answers the call of the global PYD learning agenda (YouthPower Learning, 2018) to address evidence gaps and invest in evidence-building activities related to PYD that members of the editing team spearheaded or engaged in developing. The PYD learning agenda built on evidence gaps identified in a systematic review of PYD programs (Catalano et al, 2019) and focused on themes of greatest need to apply PYD in LMICs. The articles accepted for this special issue represent efforts to bridge that divide including research-practitioner collaborations, investment by foundations and research organizations in capacity building efforts, and growing efforts to make research and knowledge more accessible, including open source. If the field is going to effectively leverage the strengths, capacities, and contributions of the global youth population to help lift people and communities out of poverty, build more civil societies, move to systems of resiliency and promote a more equitable world, the evidence base must be framed in rigorous science and be made more accessible.

\section{Thematic Framing of the Special Issue}

This special issue is organized around key topics representing the state of the field, including measurement and methods, youth voice, gender and inclusion, conflict and crisis, and a case study of program adaptation, concluding with a vision for future directions for the field.

As an opening piece to conceptually frame much of what follows, this issue begins with a thought leader commentary from USAID Agency Youth Coordinator Mike McCabe. He uses the metaphor of a Rubik's Cube to help explain the evolving approach to effective youth development, focusing on U.S. government efforts in this domain. Moving into a series of papers that provide systems-oriented perspectives on global PYD, in their paper, "Listening to Youth Through 17 Cross-Sectoral Youth Assessments: Implications for Programming and Policy," Cassandra Jessee and colleagues synthesize key policy and programming lessons from a series of studies supported by USAID and implemented by the YouthPower Learning and YouthPower2: Learning and Evaluation (YP2LE) projects from 2015-2020. A team from the International Youth Foundation comprised of John Lindsay and colleagues then share global perspective with numerous practical examples of how to integrate PYD principles throughout the program cycle. Closing the section and applying a systems approach to the important task of building the field, Clare Ignatowski and colleagues describe the Youth Systems Collaborative, 


\section{International Positive Youth Development}

a community of practice whose aim is to promote international learning on youth systems change efforts. This paper applies a global lens while also sharing case studies from Guatemala, Honduras, El Salvador, Rwanda, Mozambique, and Tanzania.

The next set of papers focuses on measurement and evidence building. First, Richard Lerner, Jonathan Tirrell, and their colleagues discuss methodological issues and options regarding longitudinal research about, and program evaluations of, PYD in low- and middle-income countries. The authors outline the steps that researchers and program evaluators should enact to address these methodological foci in their respective attempts to describe, explain, and optimize the course of positive development among diverse youth around the world. Prerna Banati and Cristina Bacalso from UNICEF follow with the results of a global gap map assessment of research on adolescent well-being to review what evidence is mapped for use by policymakers, how evidence is mapped and what evidence exists related to well-being and what evidence is still lacking. Their article is followed by an article by Carlye Gates and colleagues from both RTI and UNICEF entitled "Measuring Adolescent Participation: Results from a Qualitative Pretest in Cote D'Ivoire and Indonesia." The authors identify rigorous qualitative methods relevant to performing valid and reliable cross-cultural work with youth and for measuring and understanding youth participation across a range of international contexts.

Next we address the importance of engaging the voices of young people in defining and measuring PYD and in program implementation considerations. Patricio Cuevas-Parra from World Vision International and University of Edinburgh shares "Deconstructing the Role of Adult Facilitators in Research Led by Young People." Drawing on two case studies with young Syrian refugees and Bangladeshi young people, his paper shares lessons learned about the tensions between participation, power, and ethics when engaging young people in research efforts. The next article, by Claire O'Kane and from World Vision International, entitled "Management and Governance Accountability to Children: Participation and Representation in Organisational Decision Making" presents findings from a global landscape assessment aimed at identifying good practices and lessons learned for child and youth participation in program governance. In "Give Us More Credit! Recommendations for Young and Adult Researchers on Conducting Adolescent-Led Research," Georgiana Vasiloiu and colleagues from World Vision International explain how youth action research, youth-led research, and youth-led activism increasingly engaging youth voice in important issues and decisions about their lives are. The commentary includes two letters from young people, the first addressed to youth and the second addressed 


\section{International Positive Youth Development}

to adults, for how and why to engage young people in research and programming aimed at promoting their healthy development.

The next articles are focused on research and programming efforts aimed at promoting and better understanding the positive development of girls, an important and focal demographic in international PYD and in addressing systemic poverty around the world. The first article in the section, a thought leader commentary From Prerna Banati and colleagues is entitled "Agency and Empowerment for Adolescent Girls: An Intentional Approach to Policy and Programming." The authors share lessons learned from three case studies and argue for a girl-intentional approach to PYD policy and programming. Also contributing to this section are Prerna Kumar and colleagues from the International Centre for Research on Women with their article, "Impact of an Empowerment and Employability Program for Adolescent Girls: Evidence from India." The authors share the results of a program evaluation of Plan-It Girls, a multi-level, multistakeholder program aimed at building adolescent girls' agency and promoting gender equality. The authors share lessons learned about the program's impact on the empowerment and employability of adolescent girls and the ways to effectively engage other stakeholders. Closing out this section, Kate Plourde and her colleagues contributed "Implementation of Anyaka Makwiri: A Multicomponent Mentoring Program for Adolescent Girls and Young Women in Uganda." Their article describes the development, implementation, and results of a qualitative assessment of participant experiences in the Anyaka Makwiri program for young women aged 15 to 24 in Gulu, Uganda. Lessons learned about the curriculum and the important role of mentors are shared as are challenges to consider when working with adolescent girls.

We then examine PYD programming in conflict-affected areas and areas impacted by violence. Nalini Chugani and colleagues contribute "Resilience-Informed Positive Youth Development Programs in International Development" in which they present two case studies of PYD programming that have been used in crisis and conflict-affected areas. The case studies illustrate how resilience-informed PYD programming builds youth and community assets and agency while increasing the capacities of youth and their communities to respond to shocks and stressors common in conflict-affected settings. Holly Follmer-Reece and her colleagues contributed "On the Right Path: Youth Development Amidst Colombia's Sociocultural Transition." The authors share lessons learned from a community-based participatory research study that looks at how to effectively adapt a program from the United States to the context of Colombia. Responsive and culturally sensitive program adaptations for youth living in conflict and violent settings are described. Closing the section is an article by Betsabé Vásquez from 


\section{International Positive Youth Development}

Glasswing International and Lelys Dinarte Díaz from the Development Research Group at the World Bank Group entitled "Designing a Character Strengths Development Program for Youth Living in Violent Contexts." This paper describes the design and piloting of a character strengths development (CSD) curriculum for Glasswing International's after-school programs in El Salvador, Honduras, and Guatemala. Lessons learned are shared for CSD program design and implementation in other contexts with high levels of violence.

Next, we provide a case study of a PYD program in Senegal. As the field of PYD begins to scale internationally, the editors believe it is important to provide an example of promising practice recommendations that can serve to guide other efforts to adapt PYD models and approaches across contextual and cultural bounds. The case study entitled, "Positive Youth Development in Senegal: A Case Study of 4-H Senegal" is authored by Thomas Archibald and colleagues. In "Positive Youth Development: A Bridge to Connect Civic Education and Sustainable Development," Ashley Law and Virginia Atkinson from the International Foundation for Electoral Systems argue that civic education programs that apply a PYD approach are needed to inform and shape the democratic identities and habits of young people and that these identities and behaviors need to be effectively linked to building and sustaining democracies.

Finally, we share two articles that speak to future directions of international PYD. The first, entitled "Positive Youth Development: Parental Warmth, Values, and Prosocial Behavior in 11 Cultural Groups" by Concetta Pastorelli and her colleagues is a cross-cultural study that assesses the impact of relationships with parents and shared values about familial obligations on the prosocial behavior of children during the transition to adolescence. The article focuses on the impact of parent-child relationships on the transition to adolescence. The editors included the article in the special issue as it represents a future direction within the field that looks more intentionally at the relational and contextual developmental antecedents that help place youth on a path to positive development. The closing article, "Enhancing the International Study of Positive Youth Development: Process, Specificity, and the Sample Case of Character Virtues," is a thought leader commentary by Richard Lerner, Pam Jervis, and Marc Bornstein that focuses on the integration of research and practice in advancing international PYD. They discuss the use of the specificity principle for framing research and practice and provide the study of character virtues as an example of how PYD research and practice can and is being advanced using the specificity principle and discuss future directions for applying the specificity principle through assessing the developmental neurobiology of PYD. Finally, they discuss contributions that the 


\section{International Positive Youth Development}

integration of PYD research and practice can and is making to enhance contributions of youth to equity, social justice, and democracy.

\section{Conclusion}

We thank the contributors to this special issue, for their efforts, expertise, and engagement. We thank our peer reviewers. We extend a special shoutout and thanks to Journal of Youth Development Editor Kate Walker and to copy-editor extraordinaire, Colleen Byrne.

Lisa Lauxman thanks her co-editors, Tom, Elizabeth and Cassandra, who agreed to serve on this special issue just as COVID emerged. Our bi-weekly virtual Zoom calls created a bond forged in a mutual desire to move international PYD forward.

As a final note, while we were initiating and developing the idea for this special issue, COVID-19 began to ravage the globe. Most of the articles within this special issue were already in progress when COVID-19 hit, so few of the articles address the impact of COVID-19 on PYD efforts. We did hear from many authors during the manuscript development process about how the crisis highlighted the importance of international PYD to build and foster youth resilience and empower communities and health care systems. We have been so inspired by the stories we have heard and the efforts that are taking place around the world to keep children and youth safe and promote their healthy development. We anticipate that great learning will take place as to the impact of the pandemic on PYD and, when that happens, we imagine many of the practitioners, scholars and institutions represented in this issue will have important lessons to share.

To the Journal of Youth Development community of researchers, practitioners, reviewers and potential editors, we sincerely hope there will be continued submissions for publication of articles supporting international positive youth development.

\section{References}

Archibald, T., Guisse, B. K., Ndiaye, A., Kane, F., Diouf, F., \& Jamison, K. (2021). Positive youth development in Senegal: A case study of 4-H Senegal. Journal of Youth Development, 16(2-3), 344-362. https://doi.org/10.5195/jyd.2021.1054 


\section{International Positive Youth Development}

Banati, P., \& Bacalso, C. (2021). Adolescent well-being gap maps: What we know and opportunities for future research. Journal of Youth Development, 16(2-3), 124-158.

\section{https://doi.org/10.5195/jyd.2021.1025}

Banati, P., Rumble, L., Jones, N., \& Hendriks, S. (2021). Agency and empowerment for adolescent girls: An intentional approach to policy and programming. Journal of Youth Development, 16(2-3), 239254. https://doi.org/10.5195/jyd.2021.1071

Catalano, R. F., Skinner, M., Alvarado, G., Kapungu, C., Reavley, N., Patton, G., Jessee, C., Plaut, D., Moss, C., Bennett, K., Sawyer, S. M., Sebany, M., Sexton, M., Olenik, C., \& Petroni, S. (2019, July). Positive youth development programs in low- and middle-income countries: A conceptual framework and systematic review of efficacy. Journal of Adolescent Health, 65(1), 15-31. https://doi.org/10.1016/j.jadohealth.2019.01.024

Chugani, N. B., Faizullah, S., Janke, C., Jeudin, R., Kiernan, J., \& Wallace, N. (2021). Resilience-informed positive youth development programs in international development. Journal of Youth Development, 16(2-3), 287-309. https://doi.org/10.5195/jyd.2021.1020

Cuevas-Parra, P. (2021). Deconstructing the role of adult facilitators in research led by young people. Journal of Youth Development, 16(2-3), 175-196. https://doi.org/10.5195/jyd.2021.1034

Follmer-Reece, H. E., Velez-Gomez, P., Moratto-Vásquez, N. S., \& Dodd, S. L. (2021). On the right path: Youth development amidst Colombia's sociocultural transition. Journal of Youth Development, 16(2-3), 310-328. https://doi.org/10.5195/jyd.2021.1023

Gates, C., LeBaron, P., Flanigan, T., Murray, C., Cappa, C., Garcia-Tapia, T., Fall, S., \& Jijon, I. (2021). Measuring adolescent participation: Results from a qualitative pretest in Côte d'Ivoire and Indonesia. Journal of Youth Development, 16(2-3), 159-174. https://doi.org/10.5195/jyd.2021.1021

Ignatowski, C., Blum, R., Campbell, P. S., \& Perez-Pineda, R. (2021). Building youth infrastructure: Early lessons from the youth systems collaborative. Journal of Youth Development, 16(2-3), 74-99. https://doi.org/10.5195/jyd.2021.1030

Interagency Working Group on Youth Programs. (n.d.). https://youth.gov/youth-topics/positive-youthdevelopment

Jessee, C., Moore, A. M., Olenik, C., Trevelline, C. P., \& Taggart, N. (2021). Listening to youth through 17 cross-sectoral youth assessments: Implications for programming and policy. Journal of Youth Development, 16(2-3), 20-54. https://doi.org/10.5195/jyd.2021.1046

Kumar, P., Nuken, A., Datta, N., \& Vyas, A. (2021). Impact of an empowerment and employability program for adolescent girls: Evidence from India. Journal of Youth Development, 16(2-3), 255277. https://doi.org/10.5195/jyd.2021.1048 


\section{International Positive Youth Development}

Law, A., \& Atkinson, V. (2021). Positive youth development: A bridge to connect civic education and sustainable development. Journal of Youth Development, 16(2-3), 363-378.

\section{https://doi.org/10.5195/jyd.2021.1027}

Lerner, R. M., Jervis, P., \& Bornstein, M. H. (2021). Enhancing the international study of positive youth development: Process, specificity, and the sample case of character virtues. Journal of Youth Development, 16(2-3), 402-422. https://doi.org/10.5195/jyd.2021.1042

Lerner, R. M., Lerner, J. V., Bowers, E. P., \& Geldhof, G. J. (2015). Positive youth development and relational-developmental-systems. In W. F. Overton \& P. C. Molenaar (Eds.), Handbook of child psychology and developmental science. Theory and method ( $7^{\text {th }}$ ed., Vol. 1, pp. 607-651). Editor-in-chief: R. M. Lerner. Wiley.

Lerner, R. M., Tirrell, J. M., Gansert, P. K., Lerner, J. V., Ebstyne King, P., Geldhof, G. J., Dowling, E. M., \& Sim, A. T. R. (2021). Longitudinal research about, and program evaluations of, positive youth development in low- and middle-income countries: Methodological issues and options. Journal of Youth Development, 16(2-3),100-123. https://doi.org/10.5195/jyd.2021.1040

Lindsay, J., McGarry, S., Satmukhambetova, A., Raymond, K., Lesheve, A., Jonson, S., Neeno, H., \& Williams, C. (2021). Integrating positive youth development: Insights from international youth development programming. Journal of Youth Development, 16(2-3), 55-73. https://doi.org/10.5195/jyd.2021.1037

McCabe, M. (2021). How the Rubik's Cube helps explain the evolving approach to effective youth development. Journal of Youth Development, 16(2-3), 13-19. https://doi.org/10.5195/jyd.2021.1113

O'Kane, C., Trapp, A., Stephenson, P., \& Smith-Brake, J. (2021). Management and governance accountability to children: Participation and representation in organisational decision making. Journal of Youth Development, 16(2-3), 197-226. https://doi.org/10.5195/jyd.2021.1045

Pastorelli, C., Zuffianò, A., Lansford, J. E., Thartori, E., Bornstein, M. H., Chang, L., Deater-Deckard, K., Di Giunta, L., Dodge, K. A., Gurdal, S., Liu, Q., Long, Q., Oburu, P., Skinner, A .T., Sorbring, E., Steinberg, L., Tapanya, S., Uribe Tirado, L. M., Yotanyamaneewong, S., Al-Hassan, S., Peña Alampay, L., \& Bacchini, D. (2021). Positive youth development: Parental warmth, values, and prosocial behavior in 11 cultural groups. Journal of Youth Development, 16(2-3), 379-401. https://doi.org/10.5195/jyd.2021.1026

Plourde, K., Nanda, G., Healy, E., Kibwola, D., Mutonyi, P., Ochwo, M., Okello, F., \& Cunningham, J. (2021). Implementation of Anyaka Makwiri: A multicomponent mentoring program for adolescent girls and young women in Uganda. Journal of Youth Development, 16(2-3), 278-286.

https://doi.org/10.5195/jyd.2021.1003 
Journal of Youth Development | http://jyd.pitt.edu/ | Vol. 16 Issue 2-3 DOI 10.5195/jyd.2021.1138 International Positive Youth Development

Vasiloiu, G., Smith-Brake, J., \& Mihai, S. E. (2021). Give us more credit! Recommendations for young and adult researchers on conducting adolescent-led research. Journal of Youth Development, 16(2-3), 227-238. https://doi.org/10.5195/jyd.2021.1041

Vásquez, B., \& Dinarte Díaz, L. (2021). Designing a character strengths development program for youth living in violent contexts. Journal of Youth Development, 16(2-3), 329-343. https://doi.org/10.5195/jyd.2021.1032

YouthPower. (n.d.). https://www.youthpower.org/positive-youth-development 